\title{
THE FORMAL AND THE FORMALIZED: THE CASES OF SYLLOGISTIC AND SUPPOSITION THEORY
}

\author{
Catarina Dutilh Novaes* \\ c.dutilh.novaes@rug.nl
}

RESUMO Pode-se dizer que, enquanto disciplina, a lógica é caracterizada por dois subprojetos: teorias formais da validade de argumentos, baseadas em um número reduzido de esquemas e padrões formais, e teorias de como reduzir a multiplicidade de argumentos em contextos informais, não lógicos, ao pequeno número de padrões formais cuja validade é estudada de maneira sistemática no âmbito do primeiro subprojeto. O segundo subprojeto corresponde à noção de formalização de argumentos. Infelizmente, a tendência atual é de considerar como sendo a lógica propriamente dita exclusivamente o que se encaixa no primeiro subprojeto, em detrimento do segundo subprojeto, igualmente importante. Neste artigo, duas teorias históricas sobre a formalização de argumentos são analisadas: a teoria da silogística apresentada por Aristóteles nos "Primeiros Analíticos" e teorias medievais da suposição. Ambas ilustram o caráter duplo da lógica, que envolve dois subprojetos distintos, e contêm reflexões sofisticadas sobre como formalizar argumentos. Em ambos os casos, os métodos formais utilizados se diferenciam dos métodos atuais de tradução de um argumento em linguagem vernacular para um simbolismo especialmente formulado, ou seja, uma linguagem formal. Em conclusão, o artigo pode ser visto como a defesa de uma conceitualização mais abrangente do que significa 'formalizar' um argumento.

* Faculty of Philosophy, University of Groningen. Artigo recebido em 29/05/2014 e aprovado em 08/07/2014.

KRITERION, Belo Horizonte, nº 131, Jun./2015, p. 253-270 
Palavras-chave Silogística, Aristóteles, teoria da suposição, formalização.

ABSTRACT As a discipline, logic is arguably constituted of two main sub-projects: formal theories of argument validity on the basis of a small number of patterns, and theories of how to reduce the multiplicity of arguments in non-logical, informal contexts to the small number of patterns whose validity is systematically studied (i.e. theories of formalization). Regrettably, we now tend to view logic 'proper' exclusively as what falls under the first sub-project, to the neglect of the second, equally important sub-project. In this paper, I discuss two historical theories of argument formalization: Aristotle's syllogistic theory as presented in the "Prior Analytics", and medieval theories of supposition. They both illustrate this two-fold nature of logic, containing in particular illuminating reflections on how to formalize arguments (i.e. the second sub-project). In both cases, the formal methods employed differ from the usual modern technique of translating an argument in ordinary language into a specially designed symbolism, a formal language. The upshot is thus a plea for a broader conceptualization of what it means to formalize.

Keywords Syllogistic, Aristotle, supposition theory, formalization.

\section{Introduction}

As a discipline, logic is arguably constituted of two main sub-projects: formal theories of argument validity on the basis of a small number of patterns, and theories of how to reduce the multiplicity of arguments in nonlogical, informal contexts to the small number of patterns whose validity is systematically studied (i.e. theories of formalization). ${ }^{1}$ Ultimately, the former desperately needs the latter if a logical theory is to have any application at all to 'real life' arguments, so we might say that the portion of logical theorizing which concerns the interface between the formal and the informal, so to speak, is perhaps even more fundamental than the purely formal portion.

1 There is arguably much more to logic than the study of arguments and argumentation, but for the purposes of this paper, we will focus on this aspect of logical theorizing (which is historically very prominent anyway). 
Nevertheless, we now tend to view logic 'proper' as what falls under the first sub-project only, to the neglect of the second, equally important, sub-project.

In this paper, I discuss two historical theories of argument formalization: Aristotle's syllogistic theory as presented in the "Prior Analytics", and medieval theories of supposition. They both illustrate the two-fold nature of logic just described, as they contain illuminating reflections on how to formalize arguments in this sense. But before discussing these two theories, I begin with brief considerations on the metaphysics of arguments, which are relevant for a proper philosophical conceptualization of the formalization enterprise.

\section{The metaphysics of arguments and logical forms}

Arguments are linguistic entities in which, certain things being stated the premises - something (else) seems to follow from what has been stated - the conclusion - with varying degrees of certainty. Depending on the nature of the connection between premises and conclusions, we have different kinds of valid arguments: inductive, abductive, defeasible, deductive etc. In what follows, we focus on deductively valid arguments, which are defined as those where, given the truth of the premises, the conclusion is indeed necessarily true: in all situations where the premises are true, so is the conclusion. ${ }^{2}$ Henceforth, whenever the term 'argument' is used, it must be understood in the sense of deductive arguments.

According to a widespread view, each argument possesses a logical form, which is moreover that in virtue of which it is valid. Often, the logical form of an argument is understood as a schema, which is obtained from the original argument by replacing the non-logical terminology by schematic devices such as schematic letters, and leaving intact its logical 'skeleton'. Frequently, however, the linguistic formulation of an argument does not immediately display, in a conspicuous way, what the underlying scheme/logical form (presumably) is (which does or does not make it valid). Indeed, philosophers often contrast the surface structure and the deep structure of an argument or sentence.

We can refer to this view of arguments as the 'logical form ideology'. Despite its apparent simplicity, the logical form ideology rests on a number

2 Necessary truth-preservation is here taken to be a necessary though possibly not sufficient condition for validity. If it is necessary and sufficient, we have classical logic: sub-classical logics such as intuitionistic logic or relevant logic have additional requirements for deductive validity. 
of contentious assumptions pertaining to the metaphysics of arguments and (logical) forms. Is the logical form of an argument something that really is in the argument? Is an argument indeed composed of matter and form as its actual metaphysical constituents? Is there a principled distinction between the form and the matter of an argument? Is the (logical) form of an argument unique, or could there be more than one logical form per argument?

These questions may appear pedantic at first sight, but depending on one's answers to them, the enterprise of formalizing an argument, i.e. determining its logical form, will be conceived of in radically different ways. If the form of an argument is viewed as really in it, then formalization amounts to a process of discovery of an antecedently existing reality. If, moreover, it is thought that this reality is unique, i.e. that there is only one logical form per argument, then there can be only one correct formalization for any given argument. If, however, one resists hypostasizing the form of an argument and rejects the view that logical form is something metaphysically constitutive of it, then the enterprise of formalization is instead a creative endeavor, whereby one attributes a logical form to an argument, i.e. imposes something on it, for example for theoretical purposes. In this case, there can be a considerable amount of freedom during the formalizing process.

Elsewhere (Dutilh Novaes, 2012) I've argued against the logical form ideology, maintaining that logical form is at best something that is imposed/ attributed to an argument so that it is amenable to logical theorizing. In other words, I rejected the idea that logical form is an actual metaphysical constituent of an argument, which also entails that there is not one unique, actual logical form per argument; hence, there is no such thing as one unique adequate formalization. Thus conceived, formalization is similar to any process of modeling in the sciences and elsewhere: ${ }^{3}$ a formalization is an idealization, an approximation, not the discovery of an antecedently existing reality.

Nevertheless, there is a sense in which formalization is at the very heart of the possibility for logical theorizing, as can be observed from the very early days of the history of logic. Indeed, logic as a discipline can be described as having a two-fold nature: the formal study of argument patterns, from which judgments of validity can be made in a generalized, systematic way; and the body of procedures and techniques to turn arbitrary arguments expressed in informal, extra-theoretical terminology into formulations to which the general theory of patterns of validity can be applied. The details of these two practices 
are by and large independent of one's views on the metaphysics of arguments, but there remains the crucial issue of whether there can be only one adequate formalization for a given sentence or argument, or whether there may be different, equally legitimate formalizations.

\section{Regimentation in Aristotle's syllogistic}

As it is well known, the first chapters of Aristotle's "Prior Analytics" present a systematic study of a rather small class of arguments, namely, those composed of two premises and one conclusion, all of which display one of four possible structures, the so-called categorical sentences: 'All A is B', 'Some A is B', 'No A is B' and 'Some A is not B'. (Aristotle himself actually uses different formulations, such as 'B belongs to all A', but for convenience I will stick to the more familiar subject-copula-predicate structure.)

In the first part of Book I, Aristotle investigates which combinations of premises in this class produce necessary conclusions. For the purposes of generality and systematicity, he defines two properties of such arguments: figure and mood. Figure pertains to the mutual disposition of the three terms that must occur in a syllogistic argument: the major term is the predicate of the conclusion, the minor term is the subject of the conclusion, and the middle term is the one which occurs in both premises but not in the conclusion. The three ${ }^{4}$ figures are:

$\begin{array}{lll}\text { First } & \text { Second } & \text { Third } \\ \mathrm{A} / \mathrm{B} & \mathrm{A} / \mathrm{B} & \mathrm{B} / \mathrm{A} \\ \mathrm{B} / \mathrm{C} & \mathrm{C} / \mathrm{B} & \mathrm{B} / \mathrm{C} \\ ---- & ----- & --- \\ \mathrm{A} / \mathrm{C} & \mathrm{A} / \mathrm{C} & \mathrm{A} / \mathrm{C}\end{array}$

The mood pertains to the quantity (universal or particular) and the quality (affirmative or negative) of the sentences. In each figure, there are invalid as well as valid moods; the latter acquired special names intended as mnemonic devices in the Middle Ages: Barbara, Celarent, Darii etc.

Aristotle posits that some moods in the first figure are perfect/complete in that their validity is immediately apparent to us (later known as Barbara, 
Celarent, Darii and Ferio); thus, perfection/completion is an epistemic property of a syllogistic argument (Corcoran, 2003). He then sets off to show for all other valid moods (in all figures) that they can be deduced from the perfect syllogisms and a few other rules of inference, in particular conversion (from 'No A is B' infer 'No B is A'; from 'Some A is B' infer 'Some B is A') and subalternation (From 'All A is B' infer 'Some A is B') (Andrade-Lotero and Dutilh Novaes, 2012). For the combinations of premises and conclusion where the conclusion does not follow necessarily from the premises, he provides counterexamples, i.e. arguments displaying the mood in question with true premises and a true instantiation of the contradictory of the putative conclusion (thus showing that the putative conclusion is not necessitated by the truth of the premises in question). Eventually, he has a complete characterization of validity for this limited class of arguments (syllogistic arguments) in that for each mood in each figure it is determined whether it produces valid or invalid arguments. This is, of course, the part of the logical theory where the validity of a small number of argument patterns is investigated in a systematic way.

An absolutely crucial tool for this portion of Aristotle's theory is the use of schematic letters, for the first time in the history of logic. Historically, there seem to be interesting connections between the use of letters in logic and in mathematics in ancient Greece. Netz (Netz, 1999, chapter 1) explicitly relates the use of schematic letters by Aristotle in the two "Analytics" to the emerging practice of using letters to denote points in a diagram ('the lettered diagram', as he calls it). He hypothesizes ${ }^{5}$ that Aristotle may have been inspired by the (then already) well-established mathematical practice of using letters in diagrams for the introduction of schematic letters in his logical work. ${ }^{6}$ In effect, the generality and arbitrariness brought in by the use of letters in diagrams ("Let ABC be a triangle defined by the points A, B and C.") may have been Aristotle's inspiration to use letters to designate arbitrary terms, thus obtaining generality. But notice that the concept of schematic letter (placeholder) must be sharply distinguished from the concept of a (functional) variable, which emerged much later within mathematics: a mathematical variable stands for

5 On the basis of grammatical-linguistic considerations (Netz, 1999, pp. 48-49).

6 It is interesting to notice that the status of Aristotle's logical works as written work is debatable; the hypothesis that his texts are in fact notes taken by students during classes is viewed as quite plausible (which would explain the 'dry' style, as opposed to the much more literary style of Plato's dialogues). Again, this would suggest that the writing medium is not a necessary condition neither for regimentation nor for the use of schematic letters. 
an unknown but determinate value, whereas a schematic letter is a device of generality, indicating a range of possible instantiations. ${ }^{7}$

Be that as it may, the use of schematic letters is arguably one of the main reasons why syllogistic is a logical system even by modern standards. It deals with schemata, so that the principles and rules stated are valid for any (permissible) instantiation of the schemata with specific terms. This feature also allows for meta-properties of the system to be investigated, as done in the first chapters of the Prior Analytics.

The use of schematic devices remained pervasive in the history of logic, in particular but not exclusively in connection with syllogistic. In fact, a different ancient Greek tradition in logic (just as remarkable, but having had significantly less historical influence) also made extensive use of schematic devices: the Stoic tradition. The Stoic logicians systematically used numerals to formulate patterns of valid reasoning, but rather than standing for terms such as in Aristotelian syllogistic, the Stoic schematic devices typically stood for sentences/propositions. ${ }^{8}$ Modus ponens, for example, was thus formulated: "If the first, then the second; but the first; so the second" (modus tollens: "If the first, then the second; but not the second; so not the first").

However, the scope of application of the theory presented in the first chapters of the "Prior Analytics" would be extremely limited if it could indeed only be applied to arguments which already display the specific structure of syllogistic arguments. So especially in the second part of Book I, chapters 32 to 44 , Aristotle presents various techniques to turn non-syllogistic arguments into syllogistic ones, by regimenting the premises and conclusion so as to make them fit into one of the recognized figures/moods whose validity or invalidity has been established in previous chapters.

Here are some relevant passages from chapter 32, where Aristotle makes general comments on the regimentation enterprise. ${ }^{9}$

It is evident from the things which have been said, then, what all demonstrations come from, and how, and what things one should look to in the case of each problem. But after these things, we must explain how we can lead deductions back into the figures stated previously, for this part of our inquiry still remains. For if we should study the origin of deductions, and also should have the power of finding them, and if, moreover, we could resolve those which have already been produced into the figures previously stated, then our initial project would have reached its goal.

7 Moreover, in the modern usage of these concepts, schematic letters range over terms and variables range over objects of the domain.

8 See Bobzien (2006, section 5).

9 I am quoting the Smith translation here. Prior Analytics 47a1-22. 
First, then, one must try to pick out the two premises of the deduction $[\ldots]$; next, one must see which is universal and which is particular; and, if both should not have been taken, one must put the other premise in oneself. For sometimes people who propose a universal premise do not take the premise included in it, either in writing or in speech. Or, they propose these premises but leave out what they are concluded through and instead ask for other useless things. One must therefore see whether something superfluous has been taken, and whether one of the necessary premises has been left out; and the one should be put in and the other taken away until the two premises are reached.

Consequently, if something does result when certain things have been put, one should not try straight-off to lead it back <into the figures $>$. Instead, one must first get the two premises and next divide them in this way into terms, and that term which is stated in both the premises must be put as the middle (for the middle must occur in both of them in all of the figures).

(Finding the middle term in particular is a very important step in the regimentation of an arbitrary argument into a recognized syllogistic structure.) The regimentation is nicely illustrated in a passage from the "Prior Analytics", in a reworked version as presented by Hodges $\left(2009\right.$, p. 592).${ }^{10}$ Consider the argument:

(6) God doesn't have times that need to be set aside for action. God does have right moments for action. Therefore some right moment for action is not a time that needs to be set aside for action.

Aristotle would find the premises and the conclusion, and then write out the syllogistic terms together with letters to represent them:

(7) A: thing that God has. B: time needing to be set aside for action. C: right moment for action.

This procedure would lead to the following regimentation of the original argument (Hodges, 2009, p. 592):

(9) No (time needing to be set aside for action) is a (thing that God has). Some (right moment for action) is a (thing that God has). Therefore some (right moment for action) is not a (time needing to be set aside for action).

Why does Aristotle go through the trouble of reformulating an argument in this way? Well, simply because the argument as originally formulated would 
not be amenable to analysis with the syllogistic machinery. But once it is re-written, the (valid) syllogistic mood 'No B is A. Some C is A. Therefore some C is not B.' can be attributed to the argument. Thus, this style of regimentation marks the very birth of logic with Aristotle's syllogistic as a theory not only of the validity of argument patterns, but also of how to regiment arbitrary arguments into these patterns. ${ }^{11}$

However, the obvious philosophical question which must be asked is: in what sense is the reworked, regimented version of the argument indeed the same argument as the original, or in any case a sufficiently close counterpart thereof? One may be tempted to say that they have the same 'meaning', but this would presuppose that we have independent access to the meaning of the original argument, and are able to establish that the regimented version has the same meaning despite the linguistic dissimilarity (what Stokhof (2007) calls the 'Availability Assumption'), something that is far from uncontroversial. We may also say that the regimented version in fact depicts more conspicuously the actual, preexisting deep structure of the argument, which is there all along but in need to be discovered. But how does the formalizer obtain access to the deep structure? In practice, we all know that even in apparently simple cases, there can be serious disagreement as to what counts as the correct form/ formalization of a sentence/argument - e.g. Russell's king of France.

None of these issues is explicitly discussed by Aristotle, but it is clear that they are all lurking in the background, as his general considerations in the passages quoted above suggest.

\section{Regimentation in the Latin Middle Ages: modes of personal supposition}

Besides syllogistic, another interesting example of theories of argument formalization are Latin medieval theories of supposition, which were intended to provide a systematic account of the semantic behavior of terms and sentences. Latin medieval logic in general is characterized by a high level of regimentation of the language used. Latin medieval logicians adopted conventions related to word order so as to disambiguate some constructions:

11 Interestingly, since the 1980s the 'natural logic' movement has been promoting the study of logical reasoning in what is described as 'natural language', essentially relying on syllogistic systems (or variations thereof). It is ironic that the very birth of syllogistic is in fact marked by a move away from ordinary language; it is widely acknowledged that the categorical sentences of syllogistic were rather contrived even from the point of view of the Greek spoken at the time. Hodges (2009) very appropriately asks: what is natural about so-called 'natural logic'? 
'Every man loves a woman', for example, would be written 'A woman every man loves' if the intended reading was (in anachronistic terms) to assign wider scope to the existential quantifier. In fact, academic Latin was nobody's 'native language' at that point; it had become first and foremost a tool for intellectual inquiry, as well as for usage in other official contexts (courts of law, the Church etc.).

Supposition is usually understood by medieval authors as the property of terms (in sentences) to stand for things (Dutilh Novaes, 2011a). It is often compared to the modern concept of reference, but I've argued elsewhere (Dutilh Novaes, 2007, chap. 1) that this is a misleading and erroneous comparison. Among the different kinds of supposition that a term may have, the different modes of personal supposition are the closest medieval counterpart of modern theories of quantification (Dutilh Novaes, 2011b). They were meant to codify the quantificational behavior of what we now refer to as quantifier expressions, which the medievals classified as syncategorematic terms. Such analyses can be found in virtually every later medieval textbook in logic, but for reasons of space I shall focus on three representative texts: William of Sherwood's "Introduction to Logic", William of Ockham's "Sum of Logic" (part I), and Buridan's "Treatise on Supposition".

Perhaps the best way to understand the medieval approach to quantifier expressions by means of the notion of personal supposition ${ }^{12}$ is as a twostep procedure that explicates their meaning and semantic behavior. First, the syntactical structure of the sentence, i.e. the presence and order of its syncategorematic terms, determines the kind of personal supposition that each categorematic term has. Then, the semantic definitions of each mode of personal supposition determine the effect of quantifying syncategoremata over the quantity of objects involved in the assertion of a sentence.

In other words, the various theories of supposition presented by medieval authors typically contain two groups of rules for the modes of personal supposition: the syntactic rules mapping terms in the sentential contexts created by quantifier expressions into modes of personal supposition; and the semantic rules mapping modes of personal supposition into specific semantic behaviors. To illustrate the general idea, let us first discuss the four Aristotelian classes of categorical sentences and provide the two kinds of rules for these

12 Personal supposition is the supposition of terms for things that fall under them, i.e. of which the terms are normally predicated. But medieval authors also recognized that terms could stand for other things, such as for the corresponding universal or mental term (in which case the term is said to have simple supposition), or for appropriate linguistic entities (material supposition) (Dutilh Novaes, 2011a). In what follows, we will focus only on personal supposition. 
sentential schemata. (Notice that, even at early stages of its development, supposition theory already recognized a wide variety of quantifier expressions - unlike modern quantification theory, which started out with the existential and universal quantifiers and only later developed into a theory of generalized quantifiers. Notice also that, for medieval logicians, following Aristotle, all affirmative sentences have existential import, existential and universal sentences alike.)
(A) Every $a$ is $b$.
(E) No $a$ is $b$.
(I) Some $a$ is $b$.
(O) Some $a$ is not $b$.

\section{Syntactic rules}

The syntactic rules for these four sentential structures are easily enumerable, but in practice the enumeration of rules becomes very long when authors attempt to cover a wider range of sentential structures. The rules below can be found in all of our authors (Sherwood, "Introduction to Logic", §5.13.1; Ockham, "Sum of Logic I", chaps. 71-74; Buridan, "Treatise on Supposition", chaps. 4.3.7 and 4.3.8.):

- The positive universal syncategorema 'Every' (omnis) causes the term immediately following it to have confused and distributive supposition ( $a$ in (A)), and the term mediately following it to have merely confused supposition ( $b$ in (A)).

- A negative term, 'No' (nullus) or 'not' (non), causes all terms to its right to have confused and distributive supposition ( $a$ and $b$ in (E) and $b$ in (O)).

- The particular universal syncategorema 'Some' (alliquid) causes the term immediately following it to have determinate supposition ( $a$ in (I) and (O)).

- In the absence of syncategorematic terms immediately preceding a term, and of universal terms affecting a term mediately, a term has determinate supposition $(b$ in (I)).

\section{Semantic rules}

Authors account for the semantic behavior of the various modes of personal supposition in different ways, in particular with a clear cleavage between $13^{\text {th }}$ century and $14^{\text {th }}$ century approaches (Parsons, 1997). In the $13^{\text {th }}$ century, with Peter of Spain, William of Sherwood and Lambert of Auxerre, there was a tendency towards defining the modes of personal supposition in terms of the verification of the sentence or the supposition of its terms: 
- Supposition is determinate when the locution can be expounded by means of some single thing. Which is the case when the word supposits for some single thing. (Sherwood, "Introduction to Logic", §5.2.)

- Supposition is distributive when [the word] supposits for many in such a way as to supposit for any. (Sherwood, "Introduction to Logic”, §5.2.)

- A term has merely confused supposition in a categorical sentence when it can be taken there for several of its supposita, not necessarily for all. (For want of a satisfactory formulation of merely confused personal supposition in our authors, this is Parsons' (1997, p. 45) 'generic' version.)

By contrast, with Walter Burley, William of Ockham and John Buridan in the $14^{\text {th }}$ century, it became customary to define the modes of personal supposition in terms of 'ascent and descent', that is, in terms of the inferential relations that do or do not obtain between a sentence and the singular sentences falling under it, of the form 'This $a$ is $b$ ' (see Priest and Read, 1977; Spade, 1996, chap. 9).

Let $(\mathrm{S})$ and $(\mathrm{Q})$ stand for any syncategorematic terms, and the general form of a sentence $\mathrm{P}$ be ' $(\mathrm{Q}) a$ is $(\mathrm{S}) b$ '. The generic definitions of the modes of personal supposition in terms of ascent and descent can be formulated as (see Ockham, "Summa Logicae" I, chap. 70; Buridan, "Summulae de Suppositionibus", chaps. 4.3.5 and 4.3.6.):

- A term $a$ has determinate supposition in $\mathrm{P}=>$ A disjunction of sentences of the form 'This $a$ is (S) $b$ ' can be inferred from $\mathrm{P}$ but a conjunction of sentences of the form 'This $a$ is (S) $b$ ' cannot be inferred from $\mathrm{P}$.

- A term $a$ has confused and distributive supposition in $\mathrm{P}=>$ A conjunction of sentences of the form 'This $a$ is (S) $b$ ' can be inferred from P.

- A term $a$ has merely confused supposition in $\mathrm{P}=>$ A sentence with a disjunctive term of the form 'This $a$, or that $a$ etc... is (S) $b$ ' can be inferred from P, but neither a disjunction nor a conjunction of sentences of the form 'This $a$ is (S) $b$ ' can be inferred from $P$.

The same applies mutatis mutandis to the predicate term. Notice that among the (A), (E), (I) and (O) sentential schemata, merely confused supposition occurs only in predicate position (in (A) sentences). But more generally, it can also occur in subject position, such as in exceptive sentences of the form 'Only $a$ is b'. We thus have the concepts of propositional conjunctive descent (confused and distributive supposition), propositional disjunctive descent (determinate supposition), and nominal disjunctive descent (merely confused supposition). (What about nominal conjunctive descent? I will have more to say on it shortly.) 


\begin{tabular}{|c|c|c|}
\hline & Conjunctive & Disjunctive \\
\hline Nominal & $? ? ? ?$ & Merely confused \\
\hline Propositional & Confused and distributive & Determinate \\
\hline
\end{tabular}

By applying the two groups of rules successively (first the syntactical rules and then the semantic rules), one obtains the desired result, i.e. an account of the quantity of individuals involved in a given assertion, and thus of the semantics of quantifier expressions. For example, in 'Every man is an animal', 'man' has confused and distributive supposition and 'animal' has merely confused supposition, according to the syntactical rules for 'every'. According to the semantic rules, this sentence asserts that 'man' supposits for all of the individuals falling under it (that is, men) and that it is verified by several individuals falling under 'animal', but not by all of those falling under it.

One of the many applications of the framework is the formulation of a general theory of inferential relations between doubly-quantified sentences, which one finds for example in Buridan (Karger, 1993; Dutilh Novaes, 2004; Dutilh Novaes, 2007, chap. 3). It generates the following hexagon:

$a$ dist. $b$ dist. (1)

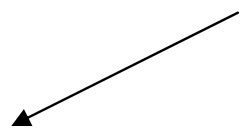

$b$ dist. $a$ dist.

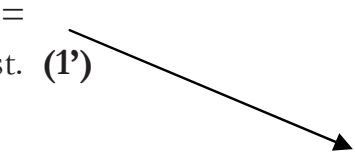

$a$ dist. $b$ det. (2)

$a$ det. $b$ dist. (2')

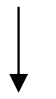

$a$ dist. $b$ conf. (3)

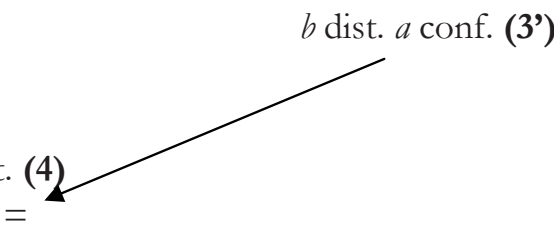

$b$ det. $a$ det. (4')

This means that a sentence where both terms have distributive supposition entails a sentence with the same terms, but where one term has distributive supposition while the other has determinate supposition. This sentence in turn 
entails a sentence with the same categorematic terms, but where one term has distributive supposition while the other has confused supposition. Finally, such a sentence entails one with the same terms, but where both terms have determinate supposition.

Naturally, just as with Aristotle's syllogistic, the applicability of supposition theory as a semantic framework, in particular for a theory of inferential relations between sentences, depends crucially on whether arbitrary sentences/arguments can be made to fit into the patterns recognized by the theory. The framework is quite flexible in that it allows for the continuous formulation of syntactic rules determining which personal supposition a term would have in a given sentential context, i.e. for different syncategoremata in different sentential contexts. But the assumption seems to be that the three traditional modes of supposition were sufficient to account for the quantificational behavior of terms in all sentential contexts. But are they really? What about nominal conjunctive descent?

At some point in the first half of the $14^{\text {th }}$ century, some authors were led to acknowledge at least the logical possibility of a fourth mode of descent, namely nominal conjunctive descent. According to (Read, 1991b, p. 74), the first mention to nominal conjunctive descent that we know of is to be found in Thomas Maulevelt's "De Suppositionibus". Maulevelt's example of the supposition of a term which is best accounted for by nominal conjunctive descent instead of nominal disjunctive descent is 'Socrates differs from every man'. According to Maulevelt, the descent allowed for the term 'man' giving the intended meaning of the sentence is 'Socrates differs from this man and that man and...', and not 'Socrates differs from this man or that man or...'. In other words, according to Maulevelt, nominal conjunctive descent is not only a logical possibility; it is also the actual descent required by some real cases, such as in this example.

Among those who recognized nominal conjunctive descent as an important phenomenon, there were two positions; either to associate nominal conjunctive descent to merely confused supposition, together with nominal disjunctive descent (as did Maulevelt and later Paul of Venice - see Read, 1991a, p. 53), yielding thus a rather heterogeneous notion of merely confused supposition as a 'miscellaneous' category; or to associate nominal conjunctive descent to a fourth mode of personal supposition altogether.

Some of the examples usually associated with nominal conjunctive descent (from Read, 1991a) were: 'You are not every man', 'No animal is every man', 'Some penny will be seen by every man' (in all three cases with respect to 'man'). But in such cases, the opponents of descensus copulatim 
usually proceeded by arguing that, if this kind of descent was possible at all, so were other kinds of descent, and therefore the supposition of such terms could after all still be classified among the three usual modes of personal supposition (since, presumably, the category of collective supposition would be defined as the cases where only nominal conjunctive descent would be possible). ${ }^{13}$ Their usual strategy consisted of an appeal to Ockham's Razor, to the effect that if the job of accounting for the different modes of personal supposition could be done with only three categories, then there was no need to posit a fourth one. ${ }^{14}$

But a fourth type of examples poses more serious difficulties. It is epitomized by the proposition 'All the apostles of God are twelve'. The nominal conjunctive descent under 'the apostles of God' is a very natural one indeed, either with demonstrative pronouns or even with proper names: 'Peter and James and John and Judas etc. are twelve'. But nominal disjunctive descent seems not to be allowed, since it is not of each of them that the predicate 'twelve' can be predicated, but rather of all of them taken collectively. ${ }^{15}$ In other words, only nominal conjunctive descent seems to be allowed, and if this kind of descent is not accounted for in the definitions of the (three) modes of personal supposition, then no mode of personal supposition seems to correspond to 'the apostles of God'.

There were different replies by those who rejected the notion of a fourth mode of personal supposition and nominal conjunctive descent, with various degrees of plausibility. Some proposed to treat 'all the apostles of God' as a singular term used to refer to the collection of apostles of God, having thus discrete supposition; others implausibly rephrased the sentence as 'All all of the apostles of God are twelve' and attributed confused and distributive supposition to the subject (Read, 1991a, p. 80). These disagreements illustrate

13 That poses a logical problem since, according to the usual laws for conjunction and disjunction, whenever nominal conjunctive descent is possible, so is nominal disjunctive descent, as indeed nominal disjunctive descent is always possible. So arguing that in such cases what we have are cases of merely confused supposition because nominal disjunctive descent is possible is in some sense fallacious, since this holds of the other modes of personal supposition as well. In this sense, collective supposition should be defined as the cases where nominal conjunctive and nominal disjunctive descents are possible, but no propositional descent is possible. However, as we shall see shortly, there are cases where nominal conjunctive descent seems to be possible but not nominal disjunctive descent, which would violate the usual rules for conjunction and disjunction.

14 An anonymous author of a commentary on Marsilius' "Parva Logicalia" says: "everything can be explained without positing collective supposition", and "one should not multiply entities without necessity" (see Read, 1991a, p. 79).

15 Indeed, this seems to indicate that the logical behavior of nominal conjunctive and disjunctive descents, or in any case the semantics of collective nouns, is more complicated than what the mere truth-functional properties of conjunction and disjunction can account for. 
once again that determining the 'unique actual logical form' of a sentence or argument is in many cases far from straightforward and unproblematic.

Historically, most authors continued to endorse the traditional list with only three modes of personal supposition. However, considered from a systematic point of view, it seems that supposition theory containing four modes of personal supposition is indeed a more sophisticated version of the traditional theory: it respects the logical symmetry of nominal and propositional descent, and it allows for a very intuitive account of the semantics of some sentential forms.

However, the main upshot is this: the theory of the modes of personal supposition is a theory of formalization, but not of the kind that we are now most familiar with: it does not consist in re-writing a given sentence or argument in some semi-artificial notation, but rather in the analysis of their semantics in terms of these concepts and definitions. Thus, this theory suggests that the concept of formalization is not restricted to the idea of reformulating an argument in ordinary language in a specially designed symbolic formal language.

\section{Conclusion}

In this paper, I have discussed two historical case studies of techniques for argument formalization. In both cases, the formal methods employed differ from the usual modern techniques of translating an argument in ordinary language into a specially designed symbolism, a formal language. Nevertheless, the process of attributing a syllogistic structure to an arbitrary argument, as we have seen, is arguably a fully-fledged process of formalization, even though the output is a rephrased argument in what can be described as a regimented (and somewhat awkward) close counterpart of ordinary language. Similarly, the procedure of accounting for the semantics of sentences and for the validity of inferences in terms of modes of personal supposition can also be seen as an instance of formalization. I plea thus for a broader conceptualization of what it means to formalize. Moreover, I briefly suggested that more attention should be paid to the metaphysics of arguments: neither Aristotle nor the medieval authors writing on the modes of personal supposition discussed these issues themselves, but it is clear that there can be no satisfactory philosophical account of what it means to formalize unless these metaphysical issues are also addressed. ${ }^{16}$ 


\section{References}

ANDRADE-LOTERO, A.; DUTILH NOVAES, C. "Validity, the squeezing argument and alternative semantic systems". Journal of Philosophical Logic, 41, pp. 387-418, 2012.

BOBZIEN, S. “Ancient logic”. In: E. Zalta (ed.). Stanford Encyclopedia of Philosophy. 2006.

CORCORAN, J. "Aristotle's Prior Analytics and Boole's Laws of Thought”. History and Philosophy of Logic, 24, pp. 261-288, 2003.

DUTILH NOVAES, C. "The Buridanian account of inferential relations between doubly quantified propositions: a proof of soundness". History and Philosophy of Logic, 25, 3, pp. 225-244, 2004.

DUTILH NOVAES, C. "Formalizing Medieval Logical Theories". Berlin: Springer, 2007.

DUTILH NOVAES, C. "Logic in the $14^{\text {th }}$ century after Ockham". In: D. Gabbay, J. Woods (eds.). The Handbook of the History of Logic. Vol. 2, pp. 433-504. Amsterdam: Elsevier, 2008.

DUTILH NOVAES, C. "Medieval Theories of Supposition". In: H. Lagerlund (ed.). Encyclopedia of Medieval Philosophy. pp. 1229-1236. Berlin: Springer, 2011a.

DUTILH NOVAES, C. "Medieval Theories of Quantification". In: H. Lagerlund (ed.). Encyclopedia of Medieval Philosophy. pp. 1093-1096. Berlin: Springer, 2011b. DUTILH NOVAES, C. "Reassessing logical hylomorphism and the demarcation of logical constants". Synthese 185, pp. 387-410, 2012.

FRIGG, R. "Models in science". In: E. Zalta (ed.). Stanford Encyclopedia of Philosophy. 2012.

HODGES, W. "Traditional logic, modern logic and natural language". Journal of Philosophical Logic, 38, pp. 589-606, 2009.

BURIDAN, J. "Summulae de Suppositionibus". Ed. R. van der Lecq. Nijmegen: Ingenium, 1998.

BURIDAN, J. "Summulae de Dialectica". Transl. G. Klima. New Haven: Yale University Press, 2001.

KARGER, E. "A theory of immediate inferences contained in Buridan's logic". In: K. Jacobi (ed.). Argumentationstheorie. pp. 407-429. Leiden: Brill, 1993.

NETZ, R. "The Shaping of Deduction in Greek Mathematics". Cambridge: CUP, 1999.

PARSONS, T. "Supposition as quantification versus supposition as global quantificational effect". Topoi, 16, 1, pp. 41-63, 1997.

PRIEST, G., READ, S. “The formalization of Ockham's theory of supposition”. Mind, 86, pp. 109-113, 1977.

READ, S. "Descensus copulatim: Albert of Saxony vs. Thomas Maulfelt”. pp. 71-85. In: J. Biard. Itineraires d'Albert de Saxe. Paris: Vrin, 1991b.

READ, S. "Thomas of Cleves and Collective Supposition". Vivarium, 29, 1, pp. 5084, 1991a. 
SMITH, R. (tr. \& comm.) “Aristotle's Prior Analytics”. Indianapolis: Hackett, 1989. SPADE, P. V. "Thoughts, Words and Things". 1996. Accessible at: <www.pvspade. com>.

STOKHOF, M. "Hand or hammer? On formal and natural languages in semantics". Journal of Indian Philosophy, 35, pp. 597-626, 2007.

WILLIAM OF OCKHAM. "Opera Philosophica I". Ed. Ph. Boehner et al. St. Bonaventure. N.Y.: The Franciscan Institute, 1974.

WILLIAM OF OCKHAM. "Summa Logicae Part I". Transl. M. Loux. South Bend: St. Augustine's Press, 1998.

WILLIAM OF SHERWOOD. "Introduction to Logic". Transl. Norman Kretzmann, Minneapolis: University of Minnesota, 1966.

WILLIAM OF SHERWOOD. "Einführung in die Logik". Ed. and German transl. H. Brands and C. Kann. Hamburg: Felix Meiner Verlag, 1995. 